\title{
PLÁGIO NA FORMAÇÃO DOCENTE: O ATALHO DOS DIAS ATUAIS
}

\author{
PLAGIARISM IN TEACHER TRAINING: THE CURRENT DAYS SHORTCUT
}

PLAGIO EN LA FORMACIÓN DOCENTE: EL CAMINO MÁS CORTO HOY DÍA

\author{
Manuelli de Souza Vasconcelos Pereira \\ Licenciada em pedagogia pelo Instituto Superior de Educação Professor Aldo. Orcid: 0000-0002-5071-2319. \\ E-mail: manuellidesouza@hotmail.com
}

\section{Carla Patrícia Quintanilha Corrêa}

Doutora em educação pela UFJF. Pós doutorado em educação pelo Instituto Superior de Educação Professor Aldo Muylaert (ISEPAM). Orcid: http://orcid.org/0000-0001-9934-8151. E-mail: carlapqcorrea@hotmail.com

\begin{abstract}
RESUMO
O presente trabalho objetiva refletir sobre a prática do plágio em textos acadêmicos, em um Curso curso de Licenciatura em Pedagogia, de uma instituição de ensino superior pública do estado do Rio de Janeiro/Brasil. Para isso, foi realizada pesquisa bibliográfica e de campo, por meio da técnica de questionário, com cinquenta e três licenciandos dos últimos períodos do curso. Os resultados apontam que a maioria dos licenciandos entrevistados compreende o que é plágio, já ouviu falar sobre tal assunto em algum momento da sua graduação e já presenciou situações de plágio durante o seu curso. Por outro lado, muitos deles têm algumas dificuldades em realizar trabalho acadêmico e, para eles, esse é um dos fatores que levam à prática do plágio, assim como a falta de tempo e a facilidade encontrada pela presença de muitos materiais prontos na internet.
\end{abstract}

Palavras-chave: Plágio. Licenciatura em pedagogia. Ética.

\begin{abstract}
This paper aims to reflect on the practice of plagiarism in academic texts in a Pedagogy Degree Course at a public higher education institution in the state of Rio de Janeiro / Brazil. Therefore, bibliographic research and field research were carried out, using the questionnaire technique, with fifty-three graduates from the last periods of the course. The results show that most of the interviewed undergraduate students understand what plagiarism is, have heard about it at some point during their graduation and have seen plagiarism during their course. On the other hand, many of them have some difficulties in carrying out academic work and, for them, this is one of the factors that lead to the practice of plagiarism, as well as the lack of time and the ease found by the presence of many ready materials on the internet.
\end{abstract}

Keywords: Plagiarism. Pedagogy course. Ethics.

\section{RESUMEN}

Este artículo tiene como objetivo reflexionar sobre la práctica del plagio en textos académicos, en un curso de Licenciatura en Pedagogía, de una institución pública de educación superior en el estado de Rio de Janeiro / Brasil. Para ello, se realizó una investigación bibliográfica y de campo, mediante la técnica del cuestionario, con cincuenta y tres estudiantes de los últimos períodos del curso. Los resultados muestran que la mayoría de los estudiantes de pregrado entrevistados entienden qué es el plagio, han oído hablar de él en algún momento durante su escolaridad y han presenciado situaciones de plagio durante su curso. Por otro lado, muchos de ellos tienen algunas dificultades para realizar un trabajo académico y, para ellos, este es uno de los factores que llevan a la práctica del plagio, así como la falta de tiempo y la facilidad con que se encuentran materiales listos en internet.

Palabras-clave: Plagio. Licenciatura en pedagogía. Princípio moral. 


\section{INTRODUÇÃO}

Este estudo aborda a questão do plágio no meio acadêmico, algo que vem ocorrendo com muita frequência. Dizemos que houve plágio quando alguém copia integral ou parcialmente a obra de determinado autor sem o referenciar, ou seja, sem que seja dado o necessário crédito ao autor daquele material.

Dessa forma, o objetivo do estudo é refletir sobre a prática do plágio em textos acadêmicos em um curso de Licenciatura em Pedagogia de uma instituição de ensino superior pública do estado do Rio de Janeiro/Brasil. Esse tema foi escolhido pelo fato de uma das autoras presenciar alguns casos de plágio durante a graduação, além de ouvir muitos relatos de professores sobre terem encontrado plágio no trabalho de colegas e em outras turmas; era perceptível que os docentes ficavam desmotivados diante de tal ato.

Para investigar tal problemática, este estudo apoiou-se em pesquisa bibliográfica e de campo, realizada por meio da aplicação de um questionário entre cinquenta e três licenciandos dos períodos finais do curso de Licenciatura em Pedagogia em questão.

Primeiramente, o artigo aborda a importância da escrita e da leitura em toda a vida escolar de uma pessoa e, principalmente, nos cursos de graduação. Em seguida, contextualiza a questão do plágio e as suas principais definições.

O artigo aborda ainda a dimensão ética em relação ao plágio, como ato inadmissível na escrita acadêmica. Por fim, apresenta o resultado da pesquisa realizada entre os licenciandos de Pedagogia, cujo foco foi investigar a sua opinião em relação à prática do plágio em textos acadêmicos.

A abordagem deste assunto intenciona suscitar reflexão no meio acadêmico, a fim de que a prática do plágio possa ser compreendida e debatida por alunos e professores.

\section{A importância da escrita autoral}

Entramos em contato com a leitura e a escrita desde muito cedo em nossa vida. Cabe à escola o desafio de despertar e manter o prazer pela leitura e a escrita ao longo dos anos de escolarização, pois estudar é um contínuo ato de estar lendo. “De ler o mundo, de ler a palavra e assim ler a leitura do mundo anteriormente feita" (FREIRE, 1997, p. 19). Não 
é somente a leitura de livros e sim a leitura de tudo aquilo que nos cerca e que estamos vivendo.

Segundo Freire (1997), no ato de ensinar o professor está em constante aprendizado e isso faz com que sempre queira buscar novos conhecimentos para se aprimorar. Em nosso campo educativo o docente tem que se inovar, pois sempre há algo novo para se fazer e aprender.

De acordo com Freire (1997), a leitura só se faz eficaz se o leitor compreender aquilo que está lendo. Ele não pode passar uma página sem entendê-la, pois a leitura não pode ser mecânica ou por pura memorização, deve ser compreendida.

A leitura e a escrita não podem ser separadas, segundo Freire (1997). Se desde os primeiros anos de escolaridade se trabalhasse com as crianças o gosto pela leitura, que se trata de algo prazeroso, e isso continuasse por toda a escolaridade, talvez não houvesse tantos graduandos relatando que não sabem escrever seus trabalhos acadêmicos.

Freire (1997) ainda sustenta que o medo é algo que tememos enfrentar, que está ligado à insegurança, fazendo-nos recuar diante do primeiro obstáculo que aparece. 0 medo está intimamente ligado à leitura e à escrita, pois, muitas vezes, antes de começarmos a ler determinado material, já estamos com medo ou inseguros se vamos compreender ou não. A mesma coisa acontece na escrita, muitas pessoas já estão tão arraigadas no pensamento de que não conseguem escrever que o medo as paralisa.

Quando se opta pela prática de educar, o sujeito necessita estar consciente de que estará lidando com pessoas, preparando-as para o futuro e para que sejam aquelas que farão a diferença. Em sua escolha deve haver responsabilidade e certeza, pois não pode ser somente uma mera escolha porque não houve outra opção.

Sabendo-se da importância da prática de educar, temos que "lutar cada vez mais eficazmente em defesa de nossos direitos [...] e estar convencidos da importância social e política de nossa tarefa" (FREIRE, 1997, p. 33); devemos fazer isso não porque a nossa tarefa seja mais importante do que as outras, mas sim porque ela é fundamental.

\section{A deterioração da escrita autoral: o plágio acadêmico}

O plágio é um problema muito recorrente na área educacional, principalmente no meio acadêmico. Ocorre quando uma pessoa usa a ideia de certo autor e não o cita em seu 
trabalho, não lhe dá créditos, copiando totalmente a sua obra, usando partes dela ou até mesmo escrevendo a ideia desse autor com suas palavras. Nesse caso, a pessoa está abusando dos direitos autorais que a obra possui e isso envolve "implicações cíveis e penais. E o desconhecimento da lei não serve de desculpa" (GARSCHAGEN, 2006, p. 3) para cometer o plágio, pois a lei é de livre acesso a todos.

Na formação acadêmica espera-se que os alunos consigam articular a ideia do autor com as próprias, para que não ocorra o plágio. Saber explicitar o que está sendo referenciado ao autor e o que são as suas ideias; ser capaz de se expressar sobre o assunto com suas próprias palavras é uma forma de avaliação dos professores no meio acadêmico.

Segundo Garschagen (2006, p. 3) existem 3 tipos de plágio:

- Plágio integral: quando o aluno copia toda a obra daquele autor sem o citar.

- Plágio parcial: quando o aluno copia um pouco da obra de vários autores e não os cita.

- Plágio conceitual: quando o aluno escreve com as suas próprias palavras, mas não cita o autor em questão.

O professor da universidade, só de olhar o trabalho, sabe se o aluno fez plágio ou não pois, com a convivência, conhece o seu aluno e, portanto, sabe como é a sua forma de escrever.

Mesmo citando o autor da obra, não se pode fazer cópia do seu trabalho, deve-se expressar a ideia utilizando as suas próprias palavras. Existem licenças para que o autor registre a sua obra e ela fique assegurada. Um exemplo delas é a Creative Commons, uma licença diferente de outras, pois nela o autor pode escolher os direitos que quer para si, ou seja, de certa forma ele pode decidir até onde o público pode usar a sua obra e as suas ideias. No modelo da Creative Commons, apenas algumas licenças são reservadas, diferente de outros modelos com todos os direitos reservados. Com isso, quando um autor opta por algum tipo de licença da Creative Commons, fica ciente de que a sua obra pode ser manipulada, distribuída, compartilhada e replicada.

Esse sistema foi criado em 2001 por Lawrence Lessig, professor da Universidade de Harvard, nos Estados Unidos, com a ideia de manter as obras dentro dos parâmetros da lei, mas também dar direito às pessoas de ter conhecimento sobre elas. Desse modo, as licenças criadas por esse sistema possibilitam ao autor oferecer alguns direitos ao público sobre a sua obra. As licenças da Creative Commons possuem níveis mais elevados, em que 
as pessoas não podem utilizar quase nada da obra original, até níveis mais leves em que o público pode usufruir de mais detalhes dela.

O Brasil já possui esse sistema, que está de acordo com a legislação brasileira e traduzido para a língua portuguesa. Vários sites oficiais utilizam esse sistema, como o da Agência do Brasil e o do Planalto; nos Estados Unidos, o da Casa Branca, entre outros.

Segundo Garschagen (2006, p. 09), as seis principais licenças da Creative Commons são (da mais leve para a mais rígida):

- Atribuição (by): A pessoa pode fazer o que quer com a obra desde que dê crédito ao autor.

- Atribuição (by-sa): A pessoa pode fazer o que quer com a obra desde que dê crédito ao autor e tenha a mesma licença dele.

- Atribuição (by-nd): A obra pode ser compartilhada ou redistribuída, ter fins lucrativos ou não, mas não pode ser modificada.

- Atribuição (by-nc): A pessoa pode fazer o que quer com a obra desde que dê crédito ao autor e que não tenha fins comerciais.

- Atribuição (by-nc-sa): A pessoa pode fazer o que quer com a obra desde que dê crédito ao autor, não tenha fins comerciais e tenha a mesma licença do autor.

- Atribuição (by-nc-nd): A pessoa pode fazer o que quer com a obra desde que dê crédito ao autor, mas não tenha fins comerciais e nem modifiquem a obra.

Seja por qualquer licença ou sistema, o autor sempre terá o seu pensamento protegido por lei. Sendo assim, os autores podem ter fins lucrativos com a sua obra. O direito autoral "se refere diretamente à obra intelectual e o direito que seu criador exerce sobre ela" (GARSCHAGEN, 2006, p. 3). A obra intelectual é quando o pensamento do autor é registrado em algum lugar.

É considerado autor de uma obra aquele que primeiro a expressou em algum lugar físico. O direito patrimonial no Brasil expira após 70 anos da morte do autor e aí passa a ser “domínio público”, já o direito moral continua sempre...

Segundo Ramos e Pimenta (2013, p. 207), com base nas Leis $n^{\circ}$ 9.610/98 (Lei de Direitos Autorais) e $n^{\circ}$ 9.609/98 (Lei do Software), $n^{\circ}$ 9.279/96 (Marcas e Patentes), e $n^{\circ}$ 9.456/97 (Cultivares), a propriedade intelectual pode ser dividida em duas categorias: o direito autoral, que consiste nas "obras intelectuais, literárias e artísticas, além dos programas de computador e domínios na internet"; e a propriedade industrial, que consiste nas "patentes, marcas, desenho industrial, indicações geográficas e proteção de cultivares". Ou seja, os direitos autorais tratam mais da escrita e a propriedade industrial da produção feita pelas indústrias. 
No momento em que estamos, a internet, a velocidade da informação e o avanço da tecnologia têm facilitado a violação dos direitos autorais. O plágio também pode ser uma conduta para obter lucro por parte de quem o pratica. Um exemplo muito comum é quando uma pessoa pede a outra para fazer o seu trabalho acadêmico por um certo preço; quem escreve o estudo, o faz praticando o plágio, para ganhar dinheiro fácil, sem ter muito trabalho.

Já se disse anteriormente que o plágio pode ser enquadrado como crime, dependendo de como se apresenta. Portanto, não é considerada conduta criminosa quando o agente faz a simples troca das palavras do trabalho original por palavras sinônimas, mas ainda assim é plágio.

É importante lembrar que, se o agente citar o nome do autor devidamente, de forma correta, mesmo que faça cópia parcial ou integral do trabalho, essa ação deixa de se configurar como crime na esfera penal e cível; isso desde que a sua finalidade seja apenas acadêmica e sem obtenção de lucro.

Muitas vezes, por acharem que não vai haver uma questão judicial, os alunos cometem o plágio e com isso os cursos de licenciaturas vêm enfrentando problemas por conta da ocorrência desta prática em trabalhos acadêmicos. Verificou-se que o ensino para pesquisa nesses cursos tem enfrentado dificuldades e, portanto, os alunos estão saindo dos mesmos sem a devida formação para a pesquisa; por consequência, provavelmente enfrentarão dificuldades no exercício profissional.

Por mais que o tema plágio possa ser abordado em diversas áreas, é nos cursos de formação de professores que a preocupação aumenta. Segundo Dias e Eisenberg (2015, p. 181):

\begin{abstract}
trata-se de refletir acerca das bases da construção do saber, de modo a tentar compreender o preocupante quadro de alunos que chegam aos cursos de licenciatura em universidades públicas, privadas ou confessionais, apresentando pouco ou nenhum domínio de processos investigativos ético-responsáveis, passam por esses cursos, repetindo um histórico de incoerência, e retornam à escola como lentes, reforçando um ciclo de diluição autoral.
\end{abstract}

Isso quer dizer que os alunos já entram nos cursos de licenciatura com uma deficiência em investigar e pesquisar, passam pelo curso com essa deficiência e vão para a sala de aula com esse mesmo problema. 
Com o fato do plágio, o ato investigativo se torna mecânico, apenas para obter notas, ao invés de conhecimento. Os textos que os alunos produzem ficam sem marca de autoria, mostrando a voz do outro e deixando apagado aquilo que deveria ser a forma pela qual o aluno se mostra crítico, investigador, pesquisador.

É preocupante o fato de que, se o licenciando não consegue fazer um trabalho de sua autoria, dificilmente conseguirá trabalhar essa habilidade com os futuros alunos. Diante disso, vê-se a necessidade de abordar o tema do plágio durante os cursos de licenciatura para que, a partir do momento em que o aluno tenha conhecimento do que é, possa eliminar ou pelo menos diminuir a sua incidência.

Dias e Eisenberg (2015, p. 183) definem o plágio:

como o ato de apropriar-se da composição, ideias ou expressão de outrem, de partes ou passagens de obras alheias, apresentando-as como produto da intelectualidade daquele que pratica o ato expropriatório.

Portanto, quem faz plágio é como se estivesse pegando o lugar do outro, a sua trajetória. O plágio envolve:

a) Cópia integral ou parcial de obra alheia sem os devidos créditos; b) Paráfrases não referenciadas - quando licenciandos modificam um pensamento de um autor, sem referenciá-lo; c) Mistura de trechos de enunciados, de modo a ludibriar o leitor, não lhe permitindo reconhecer as origens criativas do texto plagiado e levando-o a entender que o plagiador é o verdadeiro dono das partes copiadas, direta ou indiretamente; d) Autoplágio - quando um autor propõe seus textos já publicados, sem alusão aos trabalhos anteriores, criando a expectativa de algo inovador, mas deixando de contribuir com novas discussões, enganando o leitor, que acredita estar diante de algo inédito (DIAS; EISENBERG, 2015, p. 184).

O autoplágio é quando o autor toma a sua própria obra e a reescreve de forma semelhante. A autoria é trabalho de investigação baseado em diálogo, a partir disso não há problema em fazer críticas, se opor, quando se trata do pensamento em relação a outras obras que se está investigando.

Autorar se torna um “quadro cíclico” (DIAS; EISENBERG, 2015, p. 186), em que uma obra pode ser refletida, completada, ter outra interpretação e assim por diante, desde que seja da forma correta, com as devidas regras em relação ao plágio.

É muito importante que os alunos entendam a necessidade de agir eticamente na pesquisa acadêmica, pois a sua pesquisa vai ter uma repercussão social, dependendo de como foi produzida. Por isso, os futuros professores devem se conscientizar desde o início 
da sua formação sobre a sua posição ética e mediadora, para que o incentivo das criações autorais seja feito desde as primeiras séries de escolarização.

Ouvir e compreender os professores é uma forma de saber como eles estão lidando com a produção de seus alunos e como está sendo, com eles, o combate ao plágio. Mas por outro lado, também deve-se ouvir os alunos para saber o que os leva a cometer tal ato.

De acordo com Dias e Eisenberg (2015), é possível observar que a maioria dos alunos que cometem plágio diz que o faz por falta de tempo, despreparo, dificuldade na escrita e má conduta por parte dos professores. Estão ainda os casos que fazem plágio não intencional - que são aqueles que fazem tal coisa, mas não sabem que é errado.

Dias e Eisenberg (2015) sustentam que a maioria dos alunos faz citações em seus trabalhos mais pelo fato de impressionar o professor do que para expor suas próprias ideias. Por parte dos professores, vê-se que eles dão mais importância à produção autoral em trabalhos de mestrado e doutorado do que nas licenciaturas, mas esse fato tem que ser mudado, pois se continuar assim, os futuros professores vão reproduzir esse ato em sua ação futura.

Para Dias e Eisenberg (2015), quando as disciplinas específicas para construção de pesquisa são dadas logo nos primeiros períodos, os professores dos períodos seguintes entendem que os estudantes já sabem as regras e as normas e, portanto, não retomam o assunto. Mas isso pode ser um engano, pois nesse meio-tempo os alunos já esqueceram muitas coisas que foram ensinadas no início e aí se dá abertura ao plágio.

A verificação de plágio no trabalho dos alunos não deve ser um ato de punição, mas sim um ato educativo, no qual se explica ao aluno o que aconteceu para que não venha a ocorrer novamente, partindo do princípio de que muitos o fazem de forma não intencional.

Uma das maiores preocupações é a questão de os professores da educação básica não serem autores de seus próprios trabalhos e estarem lidando com a leitura e a escrita nas escolas.

Alguns pontos podem ser levados em conta para amenizar a questão do plágio, tais como:

a) deve o licenciando receber de seus professores as devidas oportunidades de ler, falar, escrever; b) devem existir nos cursos de formação de professores espaços para um acompanhamento sistemático da produção escrita do aluno (DIAS; EISENBERG, 2015, p. 186). 
Ou seja, esse último item indica que o aluno deve contar com acompanhamento de um professor para ver o que está escrevendo e mediar esse ato, se preciso. Outro ponto que também é importante é estar sempre falando de plágio dentro das instituições de ensino superior, explicando o que é para que seja de conhecimento de todos.

Lécio Ramos (apud Garschagen, 2006) aponta quatro fatores que podem contribuir para a conduta do plágio:

1- A deformação na formação educacional e intelectual de alunos, professores e demais profissionais da área; 2- A diluição ética do que é e do que não é lícito fazer; 3- A facilidade trazida pela internet, que coloca à disposição, em escala geométrica, muitos textos para quem quiser copiar; 4- A falta de tempo e pressão para produzir trabalhos (RAMOS apud GARSCHAGEN, 2006, p. 213).

Todos esses fatores citados acima contribuem e muito para a prática do assunto em questão; podem dar-se isoladamente ou muitas vezes com a junção de todos eles.

Hoje em dia a internet tem sido uma das maiores fontes de informação para os estudantes em qualquer nível de ensino. Por mais que seja uma grande aliada e de fácil acesso, muitos professores ainda não são adeptos desse recurso em sala de aula para tornar mais atraentes as suas aulas e atualizar-se. Por isso, não conseguem dirigir os seus alunos para sites seguros ao fazerem alguma pesquisa e eles acabam usando qualquer tipo de site.

Percebe-se que entre os alunos é difícil evitar a prática do plágio devido às inúmeras informações e oportunidades disponíveis na internet. Nos últimos anos, verificou-se um aumento na produção científica e com isso, consequentemente, houve um aumento no número de plágios.

Por todos esses fatores, a escrita acadêmica tem sido alvo de pesquisa de estudiosos. Em um estudo feito por Alves e Moura (2016, p. 81), com 15 licenciandos na disciplina de produção textual, duas entrevistadas se mostraram bastante próximas à escrita acadêmica e à vontade com a mesma, mas mesmo assim as duas, em sua introdução, usaram a maior parte do texto de outro artigo, apenas modificando palavras e expressões. Só lembrando que se propôs aos graduandos a escrita de um artigo científico para complementar a nota da unidade. Após a verificação da produção textual dos alunos pesquisados, perguntou-se quais seriam os fatores que explicariam a dificuldade na escrita e os três principais foram: carga horária insuficiente, falta de material teórico e conhecimento insuficiente do gênero. 
A dificuldade da produção de um novo texto baseado nas ideias de estudiosos e na sua própria visão sobre o assunto, e a falta de conhecimento e domínio do tema por parte dos alunos fazem com que os graduandos pratiquem o ato do plágio com maior frequência, ou sempre.

\section{Plágio nas diversas áreas}

Segundo Maia et al. (2017), a prática do plágio já vem ocorrendo desde os tempos mais remotos pelos filósofos e no campo da ciência. Porém, de uns anos para cá, o assunto ganhou mais destaque por conta do grande número de casos e pelo aumento das discussões acerca da ética.

Além das razões citadas anteriormente em outros textos, Maia et al. (2017, p. 2) nos dizem que outras duas razões para que o plágio aconteça são "o interesse em ampliar a quantidade de publicações e a falta de ética" e isso ocorre entre professores e pesquisadores.

Os autores citados pesquisaram qual é a percepção dos graduandos de Psicologia em relação ao plágio. Entre os alunos participantes, as palavras que mais relacionaram ao plágio foram "crime" e "cópia”. Entre alguns entrevistados, o plágio pareceu ainda um assunto não muito familiar.

A partir da pesquisa feita, ficou evidenciado que o tema em questão ainda não é claro para muitos e há várias interpretações sobre ele; por outro lado, as punições não são claras e não são padronizadas. Cada instituição age da forma que considera mais apropriada. Não há uma regra geral.

Por mais que o plágio ainda seja um tema confuso entre os estudantes e com várias interpretações, todos reconhecem que é um ato ilícito. Com o plágio ganhando cada vez mais espaço e sendo mais discutido e reconhecido como ato ilícito, pode ser que os estudantes tenham a curiosidade de buscar um pouco mais a fundo sobre o assunto e possam vir a não cometer tal ato.

Segundo Maia et al. (2017), acredita-se que o plágio ganhou mais destaque nos últimos anos por conta da necessidade de produzir e publicar mais textos, e o ato ocorre muito entre alunos e professores, principalmente pelo fato de o assunto ser pouco discutido entre eles. 
Em pesquisa de Barbastefano e Souza (2007), realizada com alunos do curso de Engenharia, constatou-se que a maioria pratica plágio pelo desconhecimento sobre o assunto. Um dos fatores para prática do plágio é o incentivo ao mesmo desde os níveis fundamental e médio, com o fato comum de ser considerado como pesquisa o recorte e colagem de imagens retiradas da internet e também a cópia de determinado assunto que foi solicitado como pesquisa.

Em estudo realizado por Batistela (2013), apontou-se que 80\% dos estudantes brasileiros não se preocupam em cometer o plágio. Para atuar contra esse problema, umas das estratégias que os professores de universidades vêm utilizando são os programas que fazem a relação entre o trabalho do aluno e textos disponíveis na internet.

Em pesquisa em um curso a distância da Licenciatura em Matemática, Batistela (2013) nos apresenta que o fato de a relação professor/aluno ser por uma plataforma e através de uma tela faz com que haja um distanciamento daquilo que o professor executou e o que o aluno entendeu. Pode ser que o que o professor explicou e pediu para que o aluno fizesse, não seja a mesma coisa que ele entendeu e vai fazer.

Ainda nessa mesma pesquisa, um trabalho foi pedido pelo professor e a turma foi dividida em quatro grupos. O professor teria quatro trabalhos para corrigir; desses quatro trabalhos, três estavam plagiados. A partir disso, estabeleceu-se um diálogo entre o professor e os alunos, pois antes da entrega do trabalho, desde o dia em foi solicitado pelo professor, foram apresentados todos os critérios de avaliação, inclusive o alerta sobre a cópia parcial ou integral de outros trabalhos. Durante o período de sua elaboração, todos esses critérios foram relembrados várias vezes e, mesmo assim, houve a prática do plágio. Portanto, não foi por falta de informação que os alunos cometeram tal ato, nem por falta de oportunidades de tirarem dúvidas, pois na plataforma havia vários espaços para isso. Além disso, o professor recolheu os trabalhos em determinada data, frisou o que estava errado, devolveu para que fossem refeitos mais de uma vez, até que estipulou uma data limite e, ainda assim, o plágio ocorreu.

Os alunos avaliados não ficaram satisfeitos com a nota que receberam, alegando ser um desrespeito dizer que o trabalho deles continha plágio, pelo trabalho e esforço que tiveram para confeccionar o que lhes foi pedido.

A partir disso, vemos a importância cada vez mais nítida de se ter uma disciplina logo nos primeiros semestres que aborde o plágio e as normas para a escrita acadêmica, pois os 
alunos relataram que não tinham tido ainda exigência desse tipo nem haviam sido informados sobre plágio e outras normas, o que dá a entender que já estão acostumados ao comportamento de copiar e colar não só na graduação, mas desde os anos anteriores de estudo.

\section{O plágio como transgressão ética}

Na década de 1980, a ideia sobre o plágio não passava do entendimento de ser uma "cola", como se faz em provas, em atividades de caderno e livros. Porém, fora do mundo da educação, o plágio já causava problemas.

Segundo Luckesi (2011), no decorrer do tempo, no Ocidente foram elencadas quatro bases para a ética; a primeira relata que a ética estava centrada no ser; na segunda o cidadão se tornou o seu próprio legislador, o que uma pessoa fazia autorizava às outras a fazer também; na terceira a conduta ética e do agir depende da situação em que o sujeito está inserido; na quarta e última, a qual é considerada a mais concreta, diz-se que a relação com o outro é um fator essencial para o agir ético.

De acordo com Luckesi (2011):

Entre os objetivos da educação para o século XXI, elaborados pela Unesco, encontra-se o anseio de "aprender a viver juntos", o que significa manter a nossa identidade e sobrevivência com dignidade, garantindo a identidade e a sobrevivência do outro também com dignidade (LUCKESI, 2011, p. 389).

A partir disso, entende-se que devemos conviver com o outro, pois em primeiro lugar somos seres de uma mesma espécie ditos “iguais” e, só depois, em segundo lugar, vem a questão de povos, etnias, grupos culturais, o que nos torna diferentes. Portanto, somos ao mesmo tempo iguais e diferentes.

Entender essa questão e assumir essa conduta é um bom início para um fundamento ético de excelência. É na relação com o outro que vamos adquirindo condutas como respeito, compaixão, compreensão, cooperação.

No meio educativo, a ética é muito importante, pois está relacionada com a conduta que o professor deve ter com o seu aluno e o compromisso que tem que ter com a aprendizagem do educando. "Eticamente, cabe ao educador ser solidário com os 
educandos, tendo em vista sua formação e sobrevivência" (LUCKESI, 2011, p. 390), pois o professor sendo solidário estará cumprindo bem o seu papel, investindo em seus alunos.

De acordo com Luckesi (2011), existem três fases do desenvolvimento ético: préconvencional, convencional e pós-convencional. Não necessariamente acontecem nessa ordem e nem todas as pessoas desenvolvem as três fases.

A fase pré-convencional se caracteriza pelo egocentrismo, tudo está centrado na pessoa, tudo é para ela e não tem nada para os outros. Na fase convencional, o sujeito cumpre exatamente com os pactos e contratos com que se comprometeu, suas exigências e suas responsabilidades. Já na fase pós-convencional ele ultrapassa o cumprimento daquilo com o que se comprometeu, fazendo o que for necessário para que a vida seja melhor, desde que não atinja a ele mesmo e não Ihe faça algum mal. Segundo Luckesi (2011), essa última é a fase mais amadurecida do desenvolvimento ético, pois o sujeito já não pensa só em si mesmo e não cumpre somente aquilo que lhe foi estabelecido. Ele vai além, fazendo o possível para que se tenha uma vida melhor.

Isso nos faz refletir que a maioria da humanidade ainda está na primeira fase e o quão importante é se inserir a ética na educação para que de alguma forma possamos mudar esse panorama.

Segundo Nosella (2008, p. 265), a pesquisa sem a ética é como "uma roda que gira cada vez mais veloz, sem rumo, sem direção", ou seja, o pesquisador que não põe em prática a ética em sua pesquisa, fica perdido e acaba se confundindo entre a sua autoria e a fala dos autores.

Os avanços da tecnologia são inúmeros, mas o problema que as pessoas não identificam neles ou que pelo menos só a minoria enxerga é a falta de ética por parte dessas novas tecnologias com o meio ambiente, a conservação do planeta e das gerações futuras.

Nesse contexto, cada vez mais os professores aspiram que os alunos tenham conhecimento sobre a ética nos trabalhos acadêmicos e a vejam de forma natural. A repercussão sobre os prejuízos causados pelo plágio só surgiu quando começou a envolver perdas financeiras. A internet vem sendo uma grande fonte de conhecimento, mas é uma grande facilitadora para a prática do plágio e uma ferramenta de detecção do plágio.

O plágio não é um problema somente do aluno, mas também do professor, pois se este faz "vista grossa” em um trabalho onde há plágio, tal problema só vai se prolongando e criando uma visão negativa em relação à integridade das profissões. Segundo Galvão e 
Luvizotto (2012), a forma errada de utilizar os textos e os seus autores está sendo uma prática cada vez maior em trabalhos que deveriam ter ética.

O ato ético está apoiado na própria consciência do sujeito e na sua relação com seus semelhantes. A partir disso, espera-se que, ao fazer uma pesquisa para um trabalho científico, o indivíduo leve em conta a ética nas buscas, sempre baseado na verdade, que não seja apenas uma pessoa ao realizar uma pesquisa e sim uma pessoa que usa a sua moral, que saiba diferenciar o bem do mal e reconhecer o que é justo ou injusto.

A ética é utilizada de diversas formas, seja para "conceituar deveres e estabelecer regras de um indivíduo seja em sua vida social, em suas atividades profissionais, em seu relacionamento com clientes e demais pessoas ou até mesmo nas amizades" (GALVÃO; LUVIZOTTO, 2012, p. 1095).

Dessa forma, percebe-se que não precisamos utilizar a ética somente no trabalho ou em uma pesquisa que fazemos. A ética está presente em nossa vida. De acordo com Galvão e Luvizotto (2012), todas as profissões têm seu código de ética, princípios éticos que devem ser seguidos.

Os valores éticos mudam no decorrer do tempo. Assim, o que era considerado ético tempos atrás, agora já não é mais. O plágio é considerado uma questão de ética há muito tempo, pois se trata da ausência de verdade. Quando se comete o ato do plágio, nada mais é do que uma verdade falsa sendo apresentada. É como utilizar o texto de outra pessoa colocando o seu próprio nome, dizendo que é de sua autoria.

De acordo com Galvão e Luvizotto (2012), existem dois tipos de virtudes: a moral e a intelectual; a intelectual é aquela que se aprende no ensino e a moral seria aquela que se aprende na prática, no fazer, no agir. É também no agir que se constrói a ética, na relação com o outro.

Cada país trata o plágio de uma maneira diferente, de acordo com suas próprias condutas, mas o que todos têm em comum é que consideram o plágio um crime.

Para que os professores consigam detectar o plágio de forma mais fácil existem alguns softwares elaborados para esse fim. Através deles, existem três tipos de categorias para identificar a prática do plágio: uma delas é a comparação entre documentos, a outra é a comparação palavra por palavra e, por último, a comparação feita por parágrafos. 
Com os casos cada vez mais recorrentes de plágio em trabalhos acadêmicos nas universidades, algumas delas desenvolveram métodos para evitarem punições e até perdas de títulos por conta de se encontrar plágio em trabalhos.

A ausência de ética em trabalhos acadêmicos demonstra a falta de capacidade do pesquisador, pois se uma pessoa copia e se apropria da obra de outra, está certificando sua incapacidade. Há algumas décadas era difícil identificar a prática do plágio, mas hoje com o avanço das tecnologias, o plágio pode ser facilmente identificado.

A ética deve estar intimamente ligada à produção científica, pois com isso o trabalho acadêmico será íntegro. O plágio primeiro é uma questão ética e depois jurídica.

A pessoa que comete plágio intencionalmente vai muito além de se apropriar de palavras de outrem, pois interfere na consciência coletiva da sociedade, que é a confiança na produção científica. Perde-se a confiança, pois se uma pessoa plagiou e passou despercebida ou não teve nenhum tipo de punição, outras irão interpretar esse fato como algo natural e irão fazer a mesma coisa, tornando-se um círculo vicioso. Com o tempo, não se poderá mais confiar em um trabalho acadêmico sem investigar se na sua produção houve plágio ou não.

A função da instituição de ensino em relação ao plágio é de suma importância, pois é onde primeiro se detecta o problema. Antes de se chegar à punição de um aluno que cometeu o ato do plágio, deve-se conscientizar todos os alunos sobre tal assunto. Se ainda assim se mantiver essa prática, a instituição poderá argumentar que fez a sua parte e o aluno não poderá alegar que tal prática foi sem intencionalidade, pois estava informado sobre o assunto.

De acordo com Pithan e Vidal (2013), o assunto não deveria ser tratado somente pelo professor orientador ou pela disciplina de produção científica, mas sim por todas as disciplinas do curso. Evitar-se-ia também a prática se o professor orientador acompanhasse todo o processo de produção do trabalho científico, desde a ideia do tema, até a apresentação do trabalho, pois assim saberia o que o aluno está escrevendo e não deixaria que tal prática ocorresse; mas percebe-se que poucos fazem este acompanhamento mais detalhado.

No decorrer da orientação, o professor deve informar ao aluno sobre a questão ética envolvida na pesquisa, a forma como deve mencionar as referências bibliográficas e reforçar o grave erro do plágio. 
Em decorrência do grande número de plágios que vem ocorrendo em diversas áreas acadêmicas, fez-se importante a realização de uma pesquisa em nossa área de atuação para verificar como os graduandos lidam com esse tema tão discutido atualmente.

\section{O plágio entre licenciandos de pedagogia}

Foi realizada uma pesquisa por meio da técnica de questionário, que contou com a participação de 53 licenciandos dos períodos finais do Curso de Licenciatura em Pedagogia, de uma instituição de ensino superior pública, do estado do Rio de Janeiro/Brasil, que responderam a 14 perguntas, feitas com o objetivo de compreender a importância da escrita acadêmica na formação dos licenciandos, bem como seu desvio por meio do plágio.

Optou-se por estabelecer os alunos concluintes como público-alvo da pesquisa, a fim de investigar se realmente estão compreendendo a questão do plágio, uma vez que já estão escrevendo o Trabalho de Conclusão de Curso (TCC).

A análise dos dados angariados por meio dos questionários foi realizada a partir das contribuições provenientes dos autores que fundamentam este estudo, levando-nos aos seguintes resultados e discussões deles decorrentes.

\section{Resultados e discussão}

Quando se perguntou sobre o que entendem sobre o conceito de plágio, 56\% dos licenciandos respondeu que plágio é o ato de copiar e colar um texto, palavras, etc. de outra pessoa como se fosse de sua autoria; $43 \%$ disse que há plágio quando se apropria das palavras de outra pessoa sem lhe dar o devido crédito; 1\% não respondeu à pergunta.

Esses resultados nos remetem a Dias e Eisenberg (2015), quando nos fornecem a definição mais comum para o plágio, não muito diferente da que os licenciandos explicitaram. Isso nos leva a concluir que conhecem o assunto, mas talvez não saibam que existem vários tipos de plágio, como nos diz Garshagen (2006), pois 56\% dos licenciandos respondeu que o plágio é a cópia exata de determinado texto.

Os dados revelam que mais da metade dos licenciandos já presenciou a abordagem do tema plágio em algum momento do curso, o que leva a concluir que o assunto é tratado na graduação, mesmo que não seja em uma disciplina específica. Isso reforça a ideia de 
Dias e Eisenberg (2015), de que se deve discutir o tema do plágio durante os cursos de licenciatura, para que os alunos não usem mais essa prática ou pelo menos que diminua a sua incidência.

Quando o assunto foi se o licenciando se considera entendedor do significado de plágio, $49 \%$ respondeu que sim, $47 \%$ em parte e $4 \%$ respondeu que não. Isso possibilita perceber que, de acordo com a opinião dos cursistas, a maioria está compreendendo o que é o assunto, mesmo que ainda tenha alguma dúvida quanto ao seu significado completo.

Em relação à questão de haver presenciado alguma situação de plágio durante a graduação, 62\% revelou que já percebeu alguma situação, 37\% não presenciou e 1\% não respondeu à pergunta. Conclui-se que, mesmo a maior parte relatando que já foi abordado o tema em sala de aula e a maioria revelando que se considera entendedor do significado de plágio, há um alto índice de situações em que ocorreu plágio entre os licenciandos. Esse resultado também leva a refletir em relação à questão ética, pois se há um alto índice de cursistas que revelam que já presenciaram situações envolvendo plágio, quem o pratica não está inserindo a ética em seu trabalho. Galvão e Luvizotto (2012) relatam que cada vez mais existem "situações de plágio em trabalhos que deveriam ser sérios e éticos" (GALVÃO; LUVIZOTTO, 2012, p. 1094).

Quando interrogados se já tiveram a oportunidade de cometer plágio, 47\% respondeu que sim e 53\% não; mesmo que a diferença seja pouca, preocupa-nos o fato de que a oportunidade de plagiar ainda seja uma realidade no ensino superior, especialmente em um curso de licenciatura. Segundo Galvão e Luvizzotto (2012, p. 1095), plagiar é uma questão ética há muito tempo, pois "se refere a uma questão de falta de verdade e moralidade ao se propor algo verdadeiro e moral". Portanto, se em um curso de licenciatura estão cometendo uma falta de ética em seus trabalhos, que deveriam ser verídicos quanto à sua autoria, questiona-se como vão orientar a seus alunos futuramente, no sentido de ensinar que isso é errado, se eles próprios o fizeram enquanto alunos.

Em relação à dificuldade em realizar trabalhos acadêmicos, 66\% relatou que encontra dificuldades e $34 \%$ não, ou seja, a maioria dos licenciandos tem dificuldades na dinâmica do trabalho acadêmico. Entre aqueles que relataram ter alguma dificuldade, a mais comum foi não conseguir escrever algo com as suas palavras, citando indiretamente o autor. Esse resultado é corroborado por Dias e Eisenberg (2015) e Alves e Moura (2016), que nos dizem que muitos casos de plágio são cometidos por haver dificuldade na escrita 
e na produção de um novo texto baseado na ideia do autor, além da falta de conhecimento sobre o tema.

De acordo com esse mesmo assunto, perguntou-se que nota, em uma escala de o a 10, o licenciando daria para seu nível de preparação ao realizar trabalhos acadêmicos; 67\% respondeu de 4 a 7; 30\% de 8 a 10; e 3\% de o a 3. A partir desse resultado, percebe-se que a maioria dos licenciandos parece enfrentar dificuldades para elaborar um trabalho acadêmico.

Os dados mostram que grande parte dos licenciandos nunca havia escutado falar sobre plágio, em nenhum lugar ou meio de comunicação; ou seja, eles chegam à graduação despreparados em relação ao tema; muitas vezes plagiavam nos anos anteriores de escolarização, sem saber do que se tratava, por falta de conhecimento.

Ainda nesse mesmo assunto, perguntou-se a opinião dos participantes da pesquisa se a maior parte dos casos de plágio é cometido intencionalmente ou por falta de conhecimento sobre o assunto. O resultado revelou que $79 \%$ respondeu que o plágio é cometido por falta de conhecimento, $18 \%$ que é intencionalmente e 3\% não respondeu à pergunta. Percebe-se que a maioria credita a prática do plágio à falta de conhecimento dos que não sabem que estão cometendo um erro.

Perguntou-se ainda se quando se faz um trabalho escrevendo com as suas próprias palavras, mas baseando-se nas contribuições de algum autor, é preciso citá-lo. Nesse caso, $92 \%$ respondeu que sim, é preciso citar o autor, e $8 \%$ respondeu que não é preciso, o que indica que a maioria está ciente de que, mesmo sendo com as suas palavras, é preciso citar o autor para não incorrer no plágio conceitual (GARSCHAGEN, 2006).

De acordo com Garschagen (2006) e o Artigo 299 da Lei n 9.610/1998, o plágio é considerado crime de falsidade ideológica em documentos particulares públicos, ou seja, documentos de autores que estão disponíveis ao acesso do público. Sobre isso, fez-se uma pergunta aos licenciandos relacionando plágio e crime. O resultado revelou que $84 \%$ respondeu que sim, o plágio é crime, $15 \%$ disse que não sabia se era ou não crime e $1 \%$ respondeu que o plágio não é crime. Diante disso, vê-se que a maior parte dos alunos tem conhecimento de que plágio está enquadrado como crime.

Diante desse quadro, alguns professores utilizam programas de computador para a detecção do plágio no trabalho dos alunos. Com isso, perguntou-se aos licenciandos se o fato de saberem que o professor utiliza algum programa para a detecção de plágio inibe 
tal prática. Para 50\%, o uso desses programas às vezes inibe a prática, 39\% responderam que sim, e 11\% respondeu que o uso de programas não inibe a prática do plágio. Portanto, metade dos alunos entrevistados considera que o fato de saber que o trabalho vai passar por um programa de detecção de plágio por vezes faz com que o indivíduo não copie.

Por último, abordou-se os fatores que levam à prática do plágio. O resultado mostrou que o que mais leva ao plágio é a falta de conhecimento e em segundo lugar a falta de tempo. Segundo Lécio Ramos (apud Garschagen, 2006), algumas das razões que levam à prática do plágio são justamente a falta de tempo e a facilidade trazida pela internet, mas, segundo Galvão e Luvizzotto (2012), mesmo que o aluno justifique que está cometendo plágio por falta de tempo, entre outros motivos, ele acaba recorrendo a algo ilegal e revelando a sua desonestidade intelectual.

Por fim, pode-se concluir que a maior parte dos licenciandos parece estar ciente do que é plágio, mas em algumas respostas ficou evidente que a falta de conhecimento sobre tal assunto é o que mais leva os alunos a plagiarem.

\section{CONSIDERAÇÕES FINAIS}

O plágio é um problema enfrentado nos últimos tempos dentro das instituições de ensino superior e não só nos cursos de licenciatura, mas também em outras áreas de graduação. Muitos são os fatores que levam à sua prática e por vezes até a falta de informação e conhecimento.

A pesquisa realizada entre concluintes do Curso de Licenciatura em Pedagogia revelou e confirmou aspectos acerca do plágio relatados por alguns autores; entre eles, os que mais se destacaram foram os fatores que levam à prática de tal ato, como a falta de conhecimento sobre o assunto, a falta de tempo e a dificuldade em escrever trabalho acadêmico.

Tal pesquisa também possibilitou concluir que a maioria dos alunos sabe do que se trata o plágio, não em seu aspecto, amplo reconhecendo as suas categorias, mas o seu conceito básico. Chama a atenção o fato de que a maior parte entende o que é plágio, mas relata que a maioria dos casos cometidos é por conta da falta de conhecimento sobre o assunto. Isso faz refletir que muitas vezes está faltando aprofundamento sobre o tema, 
pois os licenciandos entendem que é apenas um ato de copiar e colar, mas não sabem que há outras formas de se cometer plágio.

Além do que foi abordado anteriormente, ainda se deve levar em consideração que os casos de plágio trazem vários prejuízos à aprendizagem do aluno, tais como não saber articular um texto baseando-se nas ideias de um autor, não saber citar aquele determinado autor e não saber discorrer sobre determinado tema.

Sugere-se para pesquisas futuras acerca do tema, que se investigue não somente a opinião dos graduandos, mas também a dos professores. Poderá também ser feita uma pesquisa posterior com todos os períodos do curso e não apenas com os períodos finais, a fim de comparar o conceito de plágio que o licenciando traz ao chegar ao curso e quando termina a Pedagogia.

Portanto, o número de casos de licenciandos que cometem plágio ainda é significativo, o que indica a urgência da discussão acerca do tema entre alunos e professores dos cursos de graduação, especialmente os de licenciatura, a fim de serem adotadas algumas medidas para tentar fazer com que esse problema seja enfrentado coletivamente.

\section{REFERÊNCIAS}

ALVES, Maria Fátima; MOURA, Lucielma de Oliveira Batista Magalhães de. A escrita de artigo acadêmico na universidade: autoria x plágio. Ilha do Desterro, Florianópolis, v. 69, n. 3, set./dez. 2016. p. 77-93.

BARBASTEFANO, Rafael Garcia; SOUZA, Cristina Gomes de. Plágio em trabalhos acadêmicos: uma pesquisa com alunos de graduação. In: ENCONTRO NACIONAL DE ENGENHARIA E PRODUÇÃO. Anais [...]. Foz de Iguaçu: ABEPRO, 2007.

BATISTELA, Rosemeire de Fátima. O plágio numa atividade de um curso a distância. Acta Scientiae, Canoas, v. 15, n. 3, set./dez. 2013. p. 479-506.

DIAS, Wagner Teixeira; EISENBERG, Zena Winona. Vozes diluídas no plágio: a (des)construção autoral entre alunos de licenciaturas. Pro-Posições, Campinas, v. 26, n. 1, jan./abr. 2015. p. 179-197.

FREIRE, Paulo. Professora sim, tia não: cartas a quem ousa ensinar. São Paulo: Editora Olho d'Água, 1997 
GALVÃO, Agrazielle Ferreira; LUVIZOTTO, Caroline Kraus. Reflexões sobre a ética e o plágio na pesquisa científica. Colloquium Humanarum, São Paulo, v. 9, n. esp., jul./dez. 2012.

GARSCHAGEN, Bruno. Universidade em tempos de plágio. Disponível em: http://www.fev.edu.br/canais/docentes/publica/principal.php?pr=1399\&nt=54. Acesso em 21 jun. 2019.

LUCKESI, Cipriano Carlos. Avaliação da aprendizagem: componente do ato pedagógico. São Paulo: Cortez, 2011.

MAIA, Rodrigo da Silva et al. Plágio acadêmico: a percepção de estudantes de psicologia. Scientia Plena, Sergipe, v. 13, n. 8, 2017. p. 1-8.

NOSELLA, Paolo. Ética e pesquisa. Educ. Soc., Campinas, v. 29, n. 102, jan./abr. 2008. p. 255273.

PITHAN, Lívia Haygert; VIDAL, Tatiane Regina Amando. O plágio acadêmico como um problema ético, jurídico e pedagógico. Direito \& Justiça, Porto Alegre, v. 39, n. 1, jan./jun. 2013. p. 77-82.

RAMOS, François Silva; PIMENTA, Maria Alzira de Almeida. Plágio, propriedade intelectual e produção acadêmica: uma discussão necessária. Revista Eletrônica do Curso de Direito, Santa Maria, v. 8, n. 2, 2013. p. 204-214.

Recebido em: 2110/2020

Parecer em: 02/05/2021 Aprovado em: 07/06/2021 